\title{
Prevalence of potentially zoonotic gastrointestinal parasites in canine faeces in Ibadan, Nigeria
}

\section{Adekunle B. Ayinmode, Oluwasola O. Obebe and Ebenezer Olayemi}

Ghana Med J 2016; 50(4): 201-206 DOI: http://dx.doi.org/10.4314/gmj.v50i4.2

\author{
Department of Veterinary Microbiology and Parasitology, University of Ibadan, Ibadan, Oyo State, \\ Nigeria
}

Corresponding author: Adekunle Bamidele Ayinmode

E-mail: ayins2000@yahoo.com

Conflict of interest: None declared

\section{SUMMARY}

Background: Humans can get infected through direct or indirect contact with infective stages of zoonotic parasites shed to the environment through dog faeces.

Objectives: This study was designed to investigate the presence of gastrointestinal parasites present in dog faeces shed on the street of Ibadan metropolis, one of the largest cities in Africa.

Methods: Twenty-three locations were randomly selected using grid-sampling method. A total of 203 faecal samples collected from the streets of selected areas were processed for detection of helminth eggs and protozoan oocysts using flotation technique. Eggs/oocysts per gram of faeces was counted using modified McMaster technique.

Results: The prevalence of gastrointestinal parasites was 43.3\% (88/203). Single and multiple infections were 69 (78.4\%) and $19(21.6 \%)$ respectively. The parasites detected were Ancylostoma sp. 24.6\% (50/88) Isospora sp. 14.2\% (29/88), Toxocara sp. 9.8\% (20/88), Uncinaria sp. 2.5\% (5/88) and Strongyloides sp, 3.9\% (8/88). Ancylostoma sp. $\left(320 \times 10^{2} \mathrm{epg}\right)$ and Uncinaria sp. $\left(5 \times 10^{2} \mathrm{epg}\right)$ had the highest and least intensity respectively. Streets within residential areas having markets had the highest number of positive samples. All the genera of parasites detected in this study have zoonotic potential.

Conclusion: The high prevalence of zoonotic parasites detected in dog faeces from Ibadan metropolis showed that infected stray dogs roam the streets and constitute potential risk to human health. This study suggests the need for enforcement of laws restraining roaming or straying dogs and proper veterinary care of dogs.

Funding: None declared

Keywords: Dog, Faeces, Gastrointestinal Parasites, Nigeria, Zoonoses

\section{INTRODUCTION}

Dog, a very close companion to humans is often infected with different types of enteric parasites, among which Dipylidium caninum, Ancylostoma caninum, Toxocara canis, Trichuris vulpis and Echinococcus spp. have been regarded as most common. ${ }^{1,2}$ Infection by these parasites may show clinical symptom or remain asymptomatic over a long period of time. ${ }^{3}$

Dog plays important role in the epidemiology of some parasitic infections that affect humans, thereby making the control of those parasites in dogs a public health concern. ${ }^{4} 5$ Dogs shed oocysts, eggs or larvae of zoonotic parasites into the environment and humans get infected directly through contact with dog or faeces containing infective stage of the parasites or indirectly through ingestion of contaminated water and/or food. ${ }^{3}$ Two important examples of zoonotic parasites of dogs are Ancylostoma caninum and Toxocara canis. ${ }^{6,7} \mathrm{~A}$. caninum has been reported as the etiology of eosinophilic enteritis in humans. ${ }^{6}$ While, T. canis is a known cause of Visceral and Ocular Larva Migrans in humans, especially in children. ${ }^{7}$ Dogs also serve as definitive hosts to echinococcosis, a disease of major public health concern. $^{8}$

There may currently be an increase in dog population in both urban and rural settlements in developing nations, due to the use of dogs for security, hunting, breeding and other recreational activities. ${ }^{9}$ 
While some dogs are caged with adequate care, many communities still have large populations of free roaming domestic dogs without control and with little or no access to veterinary care. An increase in the population of dogs that roam the streets will increase environmental pollution with dog faeces, thereby constituting potential risk for human health due to the possibility of transmission of zoonotic parasites. ${ }^{10}$ It has been reported that wind, rain, arthropods, human and vehicular traffic can aid the spread of infective stages of parasites present in $\operatorname{dog}$ faeces to human food and water sources. ${ }^{11,12}$

Several studies have reported high prevalence of gastrointestinal parasites in dogs worldwide, Portugal ${ }^{13}$ South Africa, ${ }^{14,15}$ Egypt,${ }^{16}$ Ethiopia ${ }^{17}$ and in Nigeria; ${ }^{18-22}$ However, Information on the level of contamination by parasites shed in dog faeces on streets are lacking, especially in developing countries (including Nigeria) where control of stray dogs is not properly enforced. This study is therefore aimed at investigating the prevalence of parasites in dog faeces shed on the streets of Ibadan metropolis.

\section{METHODS}

\section{Sampling location}

This study was carried out within Ibadan the capital of Oyo State, Nigeria. The city is one of the largest cities in West Africa, located between $7^{\circ}$ and $9^{\circ} 30^{\prime}$ east of prime meridian. The mean total rainfall is $1420.06 \mathrm{~mm}$ with two peaks in June and September. The mean maximum and minimum temperatures are $26.46^{\circ} \mathrm{C}$ and $21.42^{\circ} \mathrm{C}$ respectively, and the relative humidity is $74.55 \%{ }^{23}$

Sampling sites were randomly selected by a grid sampling technique using the map of Ibadan metropolis. The 23 randomly selected locations are Poly Ibadan, Agbowo, Odo-Ona, Felele, Ijokodo, Orogun, Oritamefa, University of Ibadan, Akobo, Jericho, Molete, Aagodi, Molete grammar School, Awolowo, Beere, Eleta, Akinyemi-Challenge, Mokola, Apete-Awotan, Ajibode, UCH, Eleyele (Polo club) and Onireke.

\section{Sample collection}

Fresh faeces of dogs were collected with gloves from the streets of selected locations using plastic universal bottles, labelled and transported to the laboratory. Collected samples were then stored in the refrigerator at $4^{\circ} \mathrm{C}$ until processed the next day for ova or oocysts detection.

\section{Detection of gastrointestinal parasites}

Faecal examination was conducted for the presence of helminth eggs and/or protozoan oocysts by simple faecal centrifugation flotation technique. ${ }^{24}$ Briefly, $2 \mathrm{~g}$ of faeces was mixed with $60 \mathrm{ml}$ of sugar solution; the sample was strained through a tea strainer into test tubes and single-step centrifugation was carried out at 3000 rpm for 10 minutes. ${ }^{25} \mathrm{~A}$ plastic pipette was used to pick few drops from the top layer for a wet mount. Identification of parasitic eggs and oocysts was carried out as described by Kassai ${ }^{26}$ and Charles and Hendrix. ${ }^{27} \mathrm{Hel}-$ minths eggs and oocysts were counted using modified McMaster slide technique of Hansen and Perry. ${ }^{28}$

\section{RESULTS}

Out of 203 faecal samples collected and examined, 88 $(43.3 \%)$ were positive for eggs and oocysts of gastrointestinal parasites (Table 1).

Table 1 Percentage of single and mixed infection out of the total positive samples detected

\begin{tabular}{|c|c|c|}
\hline \multirow[t]{2}{*}{ Parasites } & & \\
\hline & $\begin{array}{l}\text { Number } \\
\text { positive }\end{array}$ & $\begin{array}{l}\text { Percent- } \\
\text { age }(\%)\end{array}$ \\
\hline Ancylostoma sp. & 50 & 56.8 \\
\hline Isospora sp. & 29 & 32.9 \\
\hline Toxocara sp. & 20 & 22.7 \\
\hline Uncinaria sp. & 5 & 5.7 \\
\hline Strongyloides sp. & 8 & 9.1 \\
\hline Ancylostoma sp. + Toxocara sp. & 1 & 1.1 \\
\hline Ancylostoma sp. + Isospora sp. & 6 & 6.8 \\
\hline $\begin{array}{l}\text { Ancylostoma sp. + Strongyloides } \\
\text { sp. }\end{array}$ & 2 & 2.3 \\
\hline Isospora sp. + Strongyloides sp. & 1 & 1.1 \\
\hline Isospora sp. + Uncinaria sp. & 3 & 3.4 \\
\hline Isospora sp. + Toxocara sp. & 2 & 2.3 \\
\hline $\begin{array}{l}\text { Ancylostoma sp. }+ \text { Strongyloides } \\
\text { sp. }+ \text { Isospora sp. }\end{array}$ & 2 & 2.3 \\
\hline $\begin{array}{l}\text { Ancylostoma sp. }+ \text { Uncinaria sp. }+ \\
\text { Isospora sp. }\end{array}$ & 3 & 3.4 \\
\hline $\begin{array}{l}\text { Isospora sp. + Uncinaria sp. }+ \\
\text { Strongyloides sp. }\end{array}$ & 1 & 1.1 \\
\hline
\end{tabular}

Table 2 Prevalence and intensity of samples with GIT parasites $(n=203)$

\begin{tabular}{lcc}
\hline Parasite species & $\begin{array}{l}\text { Intensity of infection } \\
\text { positive } \\
(\%)\end{array}$ & $\begin{array}{c}\text { (eggs or oocyst/ gram of } \\
\text { faeces) } \mathbf{~ 1 0 0}\end{array}$ \\
\hline Ancylostoma sp. & $50(24.6)$ & 320 \\
\hline Isospora sp. & $29(14.21)$ & 120 \\
Toxocara sp. & $20(9.8)$ & 170 \\
Uncinaria sp. & $5(2.45)$ & 5 \\
\hline Strongyloides sp. & $8(3.94)$ & 15 \\
\hline
\end{tabular}

Positive samples with single infection were 69 (78.4\%), while those with multiple infections were 19 (21.6\%). In all, five genera of gastrointestinal parasites were detected in all and these were Ancylostoma, Isospora, Toxo- 
cara, Uncinaria, and Strongyloides. Ancylostoma sp. ova was the highest [50 (24.6\%)] followed by Toxocara sp. [20 (9.8\%)],

Strongyloides sp. [8 (3.9\%)] and the least was Uncinaria sp. [5 (2.5\%)]. Isospora sp. 29 (14.2\%) was the only protozoan cyst detected in the samples. The intensity of infection of GI parasites expressed as egg or oocysts /gram of faeces (epg) is shown in Table 2.

Ancylostoma sp. (320 x 10 $0^{2}$ epg) and Uncinaria sp. (5 x $10^{2}$ epg) had the highest and least epg respectively. The distribution of faeces sampled by locations showed high level of ova and oocysts in dog faeces collected from streets around residential areas, markets, schools, playgrounds and business locations (Figure 1).

\section{DISCUSSION}

Littering of streets with faeces from dogs constitutes a major source of environmental pollution. ${ }^{11}$ This study found dog faeces on all the streets sampled in Ibadan metropolis. Locations included: residential areas with markets, Playground, business centres, and schools littered at varying levels with dog faeces.

This finding showed that there is high level of environmental pollution of studied area with dog faeces, indicating a high number of stray dogs roaming the streets. It is likely that the dogs were attracted to scavenge on food left over, especially in residential areas close to markets and refuse dumps. Proper environmental sanitation is recommended to reduce roaming dogs around these locations.

The high prevalence of GI parasites in faecal samples collected from streets of Ibadan metropolis is an indication of high worm burden and environmental contamination with eggs/oocysts of GI parasites. Previous studies in Nigeria $29,30,31,32$ and in other regions of the world $13,33,34$ similarly reported high level of GI infection in stray/roaming dogs. These findings affirm that environmental pollution with faeces of stray/roaming dogs is a public health concern and constitutes health hazard to human population.

Our findings like in other studies ${ }^{33,35}$ detected more helminth ova (Ancylostoma sp, Toxocara sp, Uncinaria $\mathrm{sp}$ and Strongyloides sp) than protozoan oocysts (Isospora). The disparity could be due to the fact that helminth ova are more effectively transmitted to stray dogs and could survive better in the environment than protozoan oocyst.

The result on Ancylostoma sp in this study agrees with the findings of previous investigators, ${ }^{13,22,34,36,37,38,39}$ who in their different studies reported that Ancylostoma sp. was the most prevalent among the GI parasites detected. The higher prevalence of Ancylostoma sp. over other species in this study suggests that the parasite is highly infective and efficiently transmitted to stray dogs and its ova could be maintained in expelled dogs' faeces in large numbers for a long time.

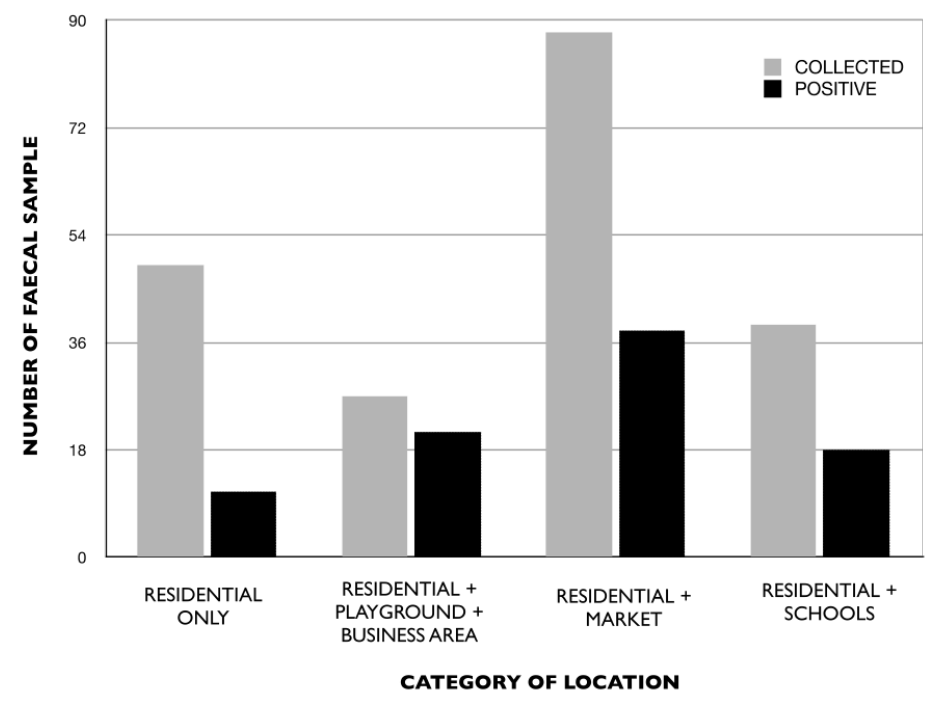

Figure 1 Showing distribution of positive dog faeces positive for parasites by type of location in Ibadan metropolis

This finding therefore necessitates sustained preventive effort to keep dog faeces off the streets, since $A$. caninum (a hook worm) has been known to cause eosinophilic enteritis ${ }^{6}$ and cutaneous larva migrans ${ }^{40}$ in infected humans. Uncinaria sp, (another zoonotic hookworm) detected at a low prevalence in this study has been known to cause conditions similar to A. caninum in infected humans. ${ }^{41}$

The high prevalence and quantity of Toxocara sp. detected in sampled dog faeces was in accordance with previous reports in Nigeria, ${ }^{29,30,31,32}$ Ethiopia, ${ }^{42,17}$ Tanzania ${ }^{43}$ and Italy. ${ }^{11}$ The high prevalence of $T$. canis in dogs has been associated with the ability of the adult parasites to shed large quantity of infective ova into the environment through dog faeces. ${ }^{44}$ T. canis infection causes visceral and ocular larva migrans in humans ${ }^{7}$ and protozoan cysts belonging to Strongyloides sp. and Isospora sp. respectively were also detected in the present study. Both parasites have been reported as agents of diarrheoa in HIV/AIDS infected persons. ${ }^{45}$

Other GI parasites of public health concern like Cryptosporidium parvum, Giardia duodenalis, Taenia sp, Dipylidium caninum that were detected by previous 


\section{Original Article}

studies $^{2,11}$ in dog faeces picked from the street were not found in the present study.

The reasons could be as a result of varying ecological and climatic conditions, difference in methods of detection and disparity in endemicity of parasites from one region to the other.

Mixed infection of GI parasites detected in this study suggests that preventive and control efforts by veterinarians and public health agencies should neither be directed to a single parasites nor a particular group (e.g. helminths or protozoan) but should be holistic in approach, since any of these zoonotic parasites could cause eruption of pathogenic conditions in infected humans.

The presence of high quantity of ova and oocysts of zoonotic parasites in dog faeces collected from streets around residential areas, markets, schools, playgrounds and business locations are evidences of readily available infection sources of these parasites to humans in studied area.

Lack of data on dogs that defecated on the streets and the inability of detection method to identify parasites to species level are the obvious limitation of this study. Nevertheless, this study provides useful information on parasites shed in dog faecal materials to the environment. This report also presents the need to keep the environment free from dog faeces in order to prevent the zoonotic diseases it could transmit to the human population.

\section{CONCLUSION}

The high prevalence of zoonotic parasites detected in dog faeces sampled from the streets of Ibadan metropolis showed that infected stray dogs that roam the streets and poses a potential risk to human health with regard to zoonoses. It is therefore necessary that policies that would keep dogs stray/roaming dogs off the street be enforced in studied area. The present study also advocates improved street (environmental) sanitation, as it would reduce kitchen waste and other items that attract scavenging dogs. Proper sanitation will also help in eliminating expelled infected $\operatorname{dog}$ faeces from the streets. It is also imperative that the public should be educated on diseases that dog faeces could transmit to humans as well as how to prevent and control such diseases. Furthermore, there is a need to review and enforce existing laws on dog owners and assess the impact of such laws regularly.

\section{REFERENCES}

1. Palmer CS, Thompson RCA, Traub RJ, Ress R, Robertson RD. National study of the gastrointestinal parasites of dogs and cats in Australia. Vet Parasitol. 2008; 151: 181-190.

2. Khante GS, Khan LA, Bodkhe AM, Suryawanshi PR, Majed MA, Suradkar US, Gaikwad, SS. Epidemiological survey of Gastro-intestinal parasites of Non-descript dogs in Nagpur City. Vet World. 2009; 2:22-23.

3. Himsworth CG, Skinner S, Chaban B, Jenkins E, Wagner BA, Harms NJ, Leighton FA, Thompson RC, Hill JE. Short report: Multiple zoonotic pathogens identified in canine feces collected from a remote Canadian indigenous community. Am. J. Trop. Med. Hyg. 2010; 83:338-341.

4. Traub RJ, Robertson ID, Irwin PJ, Mencke N, Thompson RCA. Canine gastrointestinal parasitic zoonoses in India. Trends Parasitol. 2005; 2:42-48.

5. Gracenea M, Gómez MS, Torres J. Prevalence of intestinal parasites in shelter dogs and cats in the metropolitan area of Barcelona (Spain). Acta Parasitol. 2009; 54:73-77.

6. Prociv P, Croese J, Human eosinophilic enteritis caused by dog hookworm Ancylostoma caninum. Lancet. 1990; 335: 1299-1302.

7. Larrieu E, Costa MT, Cantoni G, Alvarez R, Cavagion L, Labanchi JL, Bigatti R, Araya D, Herrero E, Alvarez E, Mancini S, Cabrera P. Ovine Echinococcus granulosus transmission dynamics in the province of Rio Negro, Argentina, 1980-1999. Vet. Parasitol. 2001; 98: 263-272.

8. Kebede M, Mitiku A, Tilahun G, Hydatidosis of slaughtered animals in Bahir Dar Abattoir, Northwestern Ethiopia. Trop Anim Health Prod. 2009; 41: 43-50.

9. Ceballos N A, Karunaratna D, Setién AA. Control of canine rabies in developing countries key features and animal welfare implications. Rev. sci. tech. Off. int. Epiz., 2014, 33 (1), 311-321.

10. Chomel BB and Ben S. Zoonoses in the bedroom. Emerg Infect Dis. 2011; 17: 167-172.

11. Tarsitano E, Greco G, Decaro N, Nicassio F, Lucente MS, Buonavoglia C. Tempesta M. Environmental monitoring and analysis of faecal contamination in an urban setting in the city of Bari (Apulia Region, Italy): Health and hygiene implications. Int J Environ Res Public Health. 2010; 7: 3972-3986.

12. Deplazes P, van Knapen F, Schweiger A, Overgaauw PAM. Role of pet dogs and cats in the transmission of helminthic zoonoses in Europe, with a focus on echinococcosis and toxocarosis. Vet Parasitol. 2011; 182: 41-53.

13. Mateus TL, Castro A, Ribeiro JN, Vieira-Pinto M. Multiple Zoonotic Parasites Identified in Dog Feces 
Collected in Ponte de Lima, Portugal - a Potential Threat to Human Health. Int J Environ Res Public Health. 2014; 11:9050-9067.

14. Mukaratirwa $\mathrm{S}$ and Busayi R. A survey of patent gastrointestinal parasites of stray dogs in Bulawayo urban area. Zimb Vet J. 1995; 26:19-27.

15. Minaar WN, Krecek RC, Fourie LJ. Helminths in dogs from a peri-urban re- source-limited community in Free State Province, South Africa. Vet Parasitol. 2002; 107: 343-349.

16. Ahmed WM, Mousa WM, Aboelhadid SM, Tawfik MM. Prevalence of zoonotic and other gastrointestinal parasites in police and house dogs in Alexandria, Egypt, Vet. World. 2014; 7 (5): 275-280.

17. Jones O, Kebede N, Kassa T, Tilahun G, Macias C, Prevalence of dog gastrointestinal parasites and risk perception of zoonotic infection by dog owners in Wondo Genet, Southern Ethiopia. J Public Health Epidemiol. 2011; 3 (11): 550-555.

18. Onyenwe IW and Ikpegbu EO. Prevalence of gastrointestinal helminths parasites (GIHP) of dogs presented at the University of Nigeria Veterinary Teaching Hospital (UNVTH) between 1994- 2002. Nig Vet J. 2004; 25 (1): 21-25.

19. Ogunkoya AB, Useh NM, Esievo KAN. The haemogram of dogs with gastrointestinal parasites in Zaria, Nigeria. J. Anim. Vet. Adv. 2006; 5 (9): 782-785.

20. Ugbomoiko US, Ariza L, Heukelbach J. Parasites of importance for human health in Nigerian dogs: high prevalence and limited knowledge of pet owners. BMC Veterinary Research. 2008; 4: 49.

21. Sowemimo OA. The prevalence and intensity of gastrointestinal parasites of dogs in Ile-Ife, Nigeria. J Helminthol. 2009; 83 (1): 27-31.

22. Okoye IC, Obiezue NR, Okorie CE, Ofoezie IE. Epidemiology of intestinal helminth parasites in stray dogs from markets in south-eastern Nigeria. $J$ Helminthol 2011; 85: 415-420.

23. Blexxonmak. Latitudes and Longitudes of major towns in Nigeria. www.nairaland.com/486575/latitudes -longitudesmajor-towns-Nigeria. 2010.

24. Foryet JW. Veterinary Parasitology: Reference Manual. 5th ed. Blackwell Inc. India. 2001; 38-39.

25. Weber R. Improved light-microscopical detection of Microsporidia spores in stool and duodenal aspirates. New Eng J Med. 1992; 326 (3): 161 - 166.

26. Kassai T. Veterinary Helminthology. ButterworthHeinemann, Boston, MS. 1999; 102-103.

27. Hendrix CM. Diagnostic Veterinary Parasitology for Technicians. Third Edition, Mosby. 2006.

28. Hansen J, Perry B. The epidemiology, diagnosis and control of gastrointestinal parasites of ruminants in Africa, Nairobi, Kenya: The International
Laboratory for Research on Animal Diseases. 1990; 107.

29. Sowemimo OA. Prevalence and intensity of Toxocara canis (Werner, 1782) in dogs and its potential public health significance in Ile-Ife, Nigeria. $J$ Helminthol. 2007; 83: 27-31.

30. Kutdang ET, Bukbuk DN, Ajayi AA. The prevalence of intestinal helminthes of dogs (Canis familiaris) in Jos, Plateau State, Nigeria. Researcher. 2010: 2: 51-56.

31. Biu AA. Aitiya G, Paul BT, Konto M. Incidence of gastrointestinal helminthes ova of Nigerian local dogs (Canisfamiliaris) resident on University of Maiduguri Campus, Maiduguri, Nigeria. J Agric Vet Sci. 2012; 4: 63-68.

32. Akeredolu $\mathrm{AB}$ and Sowemimo OA. Prevalence, intensity and associated risk factors for Toxocara canis infection in Nigerian dogs Journal of Parasitology and Vector Biology. J Parasitol Vector Biol. 2014; 6: 111-116.

33. Mukaratirwaa S and Singh VP. Prevalence of gastrointestinal parasites of stray dogs impounded by the Society for the Prevention of Cruelty to Animals (SPCA), Durban and Coast. South Africa. $J S$ Afr vet Ass. 2010; 81: 123-125.

34. Cardoso AS, Costa IM, Figueiredo C, Castro A, Conceicao MA. The occurrence of zoonotic parasites in rural dog populations from Northern Portugal. J Helminthol. 2014; 88: 203-209.

35. Labruna MB, Pena HFG, Souza SLP, Pinter A, Silva JCR, Ragozo AMA, Camargo LMA, Gennari SM. Prevalence of endoparasites in dogs from the urban area of Montenegro municipality, Rondônia. Arq Inst Biol (São Paulo). 2006; 73: 183-193.

36. Minaar WN, Krecek RC, Rajput RJ. Helminth parasites of dogs from two resource-limited communities in South Africa. J S Afr vet Ass. 1999; 70: 9294.

37. Katagiri S and Oliveira-Sequeira TCG. Prevalence of dog intestinal parasites and risk perception of zoonotic infection by dog owners in sao paulo state, Brazil. Zoonoses Public Health. 2008; 55: 406-413.

38. Mandarino-Pereira A, deSouza FS, Lopes CWG, Pereira MJS. Prevalence of parasites in soil and dog feces according to diagnostic tests. Vet Parasitol. 2010; 170: 176-181.

39. Bwalya EC, Nalubamba KS, Hankanga C, Namangala B. Prevalence of canine gastrointestinal helminths in urban Lusaka and rural Katete Districts of Zambia. Prev. Vet. Med. 2011; 100: 252-255.

40. Bowman DD, Montgomery SP, Zajac AM, Eberhard ML, Kazacos KR. Hookworms of dogs and cats as agents of cutaneous larva migrans. Trends Parasitol. 2010; 26: 162-167. 
41. Stregowski J. Zoonotic helminths from pets and wild life. A practical review and common intestinal parasites of dogs. 2007; 78-81.

42. Degefu H, Tefera A, Yohannes M. Zoonotic helminth parasites in faecal samples of household dogs in Jimma town, Ethiopia J Public Health Epidemiol. 2011; 3(4): 138-143.

43. Swai ES, Kaaya EJ, Mshanga DA, Mbise EW. A survey of gastrointestinal parasites of non-descript- dogs in around Arusha Municipality, Tanzania. Int J Anim Vet Adv. 2010; 3(2): 63-67.

44. Holland CV, Smith HV, Toxocara: The Enigmatic Parasite. CABI Publishing. 2006: 301.

45. Nissapatorn V and Sawangjaroen N. Parasitic infections in HIV infected individuals: Diagnostic and therapeutic challenges Indian J. Med., Res. 2011; 134: 878-897. 
